\title{
Rastros de Maldoror no Brasil: Lautréamont em Murilo Mendes ${ }^{1}$
}

Eliane Robert Moraes I PUC-SP

Resumo: A exemplo do que aconteceu na França-onde Lautréamont só se tornou conhecido no século $X X$-, no Brasil é igualmente difícil falar da repercussão de sua poética antes do Modernismo. Entre os autores do movimento que se deixaram atravessar por sua voz, ganha destaque a figura de Murilo Mendes, que evoca o criador de Maldoror como "o jovem sol negro / que inaugura nosso tempo". Para além das referências explícitas, os poemas do modernista brasileiro revelam uma afinidade de fundo com os escritos de Ducasse, sobretudo quando interrogam os fundamentos da identidade. Se a obra de Lautréamont deixa manifesta a intenção de apagamento do "eu", abrindo espaço para uma literatura "feita por todos", semelhante desejo é expresso por Murilo Mendes, cuja poesia insiste em afirmar as múltiplas faces de um sujeito lírico que jamais cede ao projeto de compor um retrato único. Palavras-chave: Lautréamont, Murilo Mendes, Maldoror, Ducasse, Modernismo brasileiro.

1. Este texto retoma, com diversos acréscimos e modificações, minha palestra no Colóquio Internacional "Semana Lautréamont - l'autre de la littérature", realizado na Universidade Autônoma de Barcelona, Espanha, entre 20 e 25 de Novembro de 2006. Foi publicada nos anais do evento, sob o título "Échos de Maldoror au Brésil: la poésie de Murilo Mendes" In: RIPOLL. Lautréamont - l'autre de la littérature. 
Publicado por um certo Du Boisaymé, em 1811, o incógnito trabalho acadêmico intitulado De la courbe que décrit un chien courant après son mâ̂tre está na origem de uma das mais notáveis imagens que o Conde de Lautréamont propõe em Les chants de Maldoror. É no canto V que o poeta se vale desse insólito estudo para definir o estranho "bufo de Virgínia", portentosa ave noturna que se recolhe nas reentrâncias de um convento em ruínas depois de sangrenta luta nos ares com um abutre, sendo objeto da seguinte analogia: "bela como uma dissertação sobre a curva descrita por um cão correndo atrás de seu dono". ${ }^{2}$

Imagem potente para evocar a força dos rastros, a curva em questão é resultado de um grande dispêndio de energia. Porém, seja identificada à linha desenhada pelo cão que acompanha os passos de seu dono, seja ao rastro dos volteios rápidos e fugazes da grande ave, ela parece sempre aludir aos esboços fugidios, que não deixam qualquer vestígio palpável. Dissertar sobre matéria ao mesmo tempo tão efêmera e potente por certo supõe um risco, mas tudo leva a crer que é justamente esse risco que sustenta a beleza paradoxal das analogias de Ducasse.

O que se deseja descrever aqui também é o contorno de uma linha sinuosa. Menos paradoxal e menos poética, mas igualmente esquiva e arriscada, trata-se da curva formada pelos traços que um escrito imprime em outro, e assim por diante. Trata-se, portanto, de imaginar as possíveis reverberações de um texto, na tentativa de capturar aquelas impressões que, nascidas no momento fugaz da leitura, reaparecem com força no tecido da escrita, mas envoltas por uma opacidade característica dos rastros, dos vestígios, dos ecos.

Ora, no capítulo das reverberações, a literatura de Lautréamont não tem paralelos. Como já observaram muitos estudiosos, a paródia foi o grande motor da criação poética de Ducasse: no romantismo exasperado dos Cantos, cujo exagero macabro tem sido creditado às citações de Sade, Poe, Eugène Sue e sobretudo do roman noir, são reconhecidas passagens de Homero, de Dante, de Goethe, do Apocalipse, além de uma variedade de enciclopédias, almanaques, revistas e folhetins, entre outros. De fato, a obra ducassiana pode ser lida como uma imensa e notável colagem de outros autores e textos, realizada ora por meio

2. No original: "beau comme un mémoire sur la courbe que décrit un chien en courant après son maître". RIMBAUD; LAUTRÉAMONT; CORBIÈRE; CROS. Euvres poétiques complètes, p. 717. (Para a tradução brasileira, consultar: LAUTRÉAMONT. Os cantos de Maldoror, p. 223). 
de referências mais ou menos longínquas, ora por meio de transcrições literais, método que atinge a perfeição nas Poesias. Sabe-se que até mesmo a afirmação de que "a poesia deve ser feita por todos, e não por um" consiste em citação adulterada de Vauvenargues, escritor do século XVIII, o que só faz reiterar a fórmula categórica do poeta: "o plágio é necessário".

Não é de estranhar, pois, que uma obra feita de tantos ecos também ecoe com intensidade em outros textos literários, deixando transparecer uma espécie de conversa subterrânea que se trava entre vozes poéticas distintas, de tempos e espaços igualmente diversos. Assim, para além mesmo das relações genéticas, pode-se tomar a escrita de Lautréamont como uma "obra de referência", tal como entende Roland Barthes quando define a literatura de Proust como uma forma de "lembrança circular", como "mathesis geral", ou mesmo como "mandala de toda a cosmogonia literária". Imagens que por certo evocam o movimento indomável do tempo, sem o qual talvez seja impossível descrever a curva das ressonâncias de Maldoror.

\section{II}

Rastros de Maldoror no Brasil: a expressão poderia sugerir um extenso balanço da leitura de Lautréamont no país. Embora não seja o intuito deste texto, convém lembrar que um tal rastreamento, ainda não realizado, seria bastante oportuno, tanto para corroborar com os estudos ducassianos quanto para ampliar a compreensão da própria literatura brasileira, quiçá prometendo boas surpresas. Apesar de haver suposições de que o autor possa ter influenciado alguns de nossos literatos do final do século XIX, o sinal mais antigo da sua presença entre nós data de 1901, quando teria sido feita a primeira transcrição dos Cantos, assinada por Saturnino Meirelles, obstinado discípulo do poeta simbolista Cruz e Souza. ${ }^{4}$

A exemplo do que aconteceu na França - onde Lautréamont só se tornou realmente conhecido no século XX -, também no Brasil fica difícil falar da repercussão de sua voz antes do Modernismo. Por isso, interrogar sua presença na paisagem literária nacional implicaria sobretudo a investigação das diversas formas de contato que se estabeleceram entre vanguardistas brasileiros e franceses a

3. BARTHES. O prazer do texto, p. 49.

4. Cf. LIMA. Alguns dados sobre a construção interessada de uma ausência: a do surrealismo no Brasil ou... "a cada um o seu desejo", p. 202. 
partir da década de 1920, o que excede a visada deste texto. ${ }^{5}$ Vale recordar, contudo, que as viagens europeias de nossos modernistas, aliadas às estadias de escritores como Benjamin Péret e Blaise Cendrars no país, foram decisivas para a ampliação do horizonte literário dos artistas ligados ao movimento, alguns deles atentos leitores dos surrealistas, como é o caso de Jorge de Lima, Oswald de Andrade, Lúcio Cardoso, Cornélio Pena, Mário Pedrosa ou Aníbal Machado.

Entre esses autores, ganha destaque a figura do poeta Murilo Mendes, que qualificou sua descoberta do surrealismo como "um coup de foudre", de intensa repercussão não só para si, como também para o amigo pintor Ismael Nery, que havia passado um longo período na França. Segundo seu entusiástico registro, "tratava-se de explorar o subconsciente; tratava-se de inventar um outro frisson nouveau, extraído à modernidade; tudo deveria contribuir para uma visão fantástica do homem e suas possibilidades extremas". . Apesar de católico, Mendes se entregou a essa liberdade de espírito proposta pelo movimento, na contramão da vertente hegemônica do modernismo brasileiro, mais preocupada em redefinir a identidade nacional a partir de novos parâmetros.

5. Elementos para uma história da presença de Lautréamont no Brasil, além do número da revista Organon acima indicado, podem ser encontrados também em: CÂNDIDO. Surrealismo no Brasil; PAES. O surrealismo na literatura brasileira, p. 99-114; FARIAS. O surrealismo na poesia de Jorge de Lima; PONGE. Surrealismo e Novo Mundo.

6. Cf. BARRoso. A obra maldita de Lautréamont, p. D4. É, portanto, no centro do Modernismo brasileiro que se encontram os primeiros admiradores confessos de Ducasse, os quais inauguram uma tradição de leitura que só fez crescer ao longo do século XX, com particular repercussão nos anos 1960-1970, quando alguns artistas da chamada contracultura vão manifestamente se reclamar herdeiros de Lautréamont. Convém citar, nesse caso, os nomes dos escritores Roberto Piva e Cláudio Willer, este último tradutor da obra completa do poeta oitocentista que, publicada originalmente em 1970, contou com sucessivas reedições desde então. No âmbito literário, cumpre assinalar ainda a iniciativa recente do escritor Ruy Câmara, que publicou uma biografia imaginária do criador de Maldoror. Em paralelo ao interesse despertado pelo poeta francês em escritores brasileiros, há que se referir também ao notável trabalho crítico de Leyla Perrone-Moisés, inaugurado no início dos anos 1970 com o livro Falência da crítica e continuado em outros ensaios. Ver em especial: CÂMARA. Contos de outono; PERRONE-MOISÉS. A falência da crítica; e PERRONE MOISÉS; RODRÍGUEZ MONEGAL. Lautréamont austral.

7. MENDES. André Breton, p. 1.238. 
Não surpreende portanto que, entre as obras modernistas, sejam seus os escritos que fazem as referências mais explícitas à figura de Ducasse, a quem Murilo evocou como "o jovem sol negro / que inaugura nosso tempo". 8 Em uma das prosas de Poliedro, por exemplo, o autor propõe uma breve e bem humorada definição do Uruguai que alude diretamente ao autor:

O Uruguai é um belo país da América do Sul, limitado ao norte por Lautréamont, ao sul por Laforgue, a leste por Supervielle.

As principais produções do Uruguai são: Lautréamont, Laforgue e Supervielle.

O Uruguai conta com três habitantes: Lautréamont, Laforgue e Supervielle, que formam um governo colegiado. Os outros habitantes acham-se exilados no Brasil visto não se darem nem com Lautréamont, nem com Laforgue, nem com Supervielle.

Brincadeira? Pode ser, mas por certo uma brincadeira séria e expressiva, expondo a situação de isolamento e incompreensão crítica que o surrealismo enfrentou no Brasil, com forte impacto na recepção da obra do próprio Murilo. Como anotaram alguns comentadores, a tendência a minimizar a importância surreal na produção do escritor impediu a crítica brasileira de perceber sua afinidade com a atitude rebelde e libertária do movimento capitaneado por Breton. Desnecessário dizer que tal resistência impediu também a identificação de qualquer marca ducassiana na poesia do brasileiro, não obstante ele mesmo ter incluído o poeta franco-uruguaio na declaração de princípios intitulada "Microdefinição do Autor" onde lista seus grandes inspiradores.

É significativo, pois, que o pequeno texto sobre o "Uruguai" manifeste o reconhecimento de um país vizinho ao Brasil a partir desses três homens que, tendo lá nascido por acaso, são célebres autores da literatura francesa. Ora, isso supõe a afirmação de uma outra forma de vizinhança que, indiferente às

8. MENDES. Homenagem a Jorge de Lima, p. 555.

9. MENDES. Uruguai, p. 1.023.

10. Ver, em especial, MERQUIOR. À beira do antiuniverso debruçado ou introdução à obra de Murilo Mendes; MASSI. Murilo Mendes: a obra do poliedro; ARRIGUCCI. Arquitetura da memória.

11. Ver MENDES. Murilo Mendes - o menino experimental. 
contiguidades territoriais, busca estabelecer cumplicidades de pensamento. Supõe igualmente a descoberta de uma comunidade que se situa fora de qualquer delimitação nacional, como evidencia também o "retrato-relâmpago" que o poeta brasileiro dedica ao criador de Maldoror, já desde sua primeira frase: "Debruçado numa janela não de Paris nem de Montevidéu, Lautréamont descobre, pensa, vê, imagina, inventa, redescobre, repensa, revê, reimagina, reinventa, coisas, objetos, seres e situações intercambiáveis."

Aqui se esboça claramente essa ideia de um lugar outro, imaginário, onde tudo é passível de desdobramento - uma vez que lá se pode pensar e repensar, inventar e reinventar, ver e rever, e assim sucessivamente. Ideia reforçada ao longo desse breve e penetrante retrato, conforme reitera a passagem que apresenta Ducasse como o "confidente sexual da noite (...) que assiste à cópula das irmãs siamesas”, onde o duplo vem associar-se à potência do erotismo. Tratase, pois, de realçar a força da repetição, mas não de uma repetição qualquer, fruto de simples mecânica sem vigor: ao contrário, o que se supõe aqui é uma operação de desdobramento no sentido de ampliar a intensidade do ato inicial, "contribuindo para reforçar o enigma, razão primeira da poesia”. ${ }^{13}$

Assim, se a janela onde Murilo vê Lautréamont se debruçar não se localiza em território passível de delimitação, isso acontece porque esse lugar de observação é puramente poético. Tudo leva a crer, portanto, que esse mundo duplicado onde ocorre um acréscimo de intensidade, tal como suposto pelo escritor, não é outro senão o próprio mundo da poesia. Daí que o autor dos Cantos de Maldoror não esteja na França, nem no Uruguai, nem no Brasil, ou em qualquer outra nação, já que ele habita um país fictício, fantasmático, sem território - ou, para nos valermos de um adjetivo caro aos surrealistas, um país dépaysé.

III

Ao país desterritorializado corresponde uma identidade igualmente dépaysée. É a ela que Murilo Mendes se refere num poema que, escrito originalmente em italiano, supõe franca adesão aos artifícios do jovem poeta oitocentista:

12. MENDES. Lautréamont, p. 1280.

13. MENDES. Lautréamont, p. 1281. 
Compiuti ventiquattro anni

Cosa se potrebbe fare a Parige o altrove

Nell'Ottocento? Essere se stesso stanca

Essere Isidoro Ducasse stanca

Ti cambiasti allora in Lautréamont. ${ }^{14}$

O interesse despertado por esses versos está no fato de que, ao escrevê-los em outra língua, o modernista brasileiro também acaba duplicando sua própria persona poética, como que participando do vertiginoso processo de desterritorialização que marca a identidade ducassiana. Escusado dizer que, nos Chants, é impossível discernir o criador da criatura, sendo que cada qual remete a uma sucessão de desdobramentos. Recorde-se que a epopeia de Maldoror é às vezes narrada pelo suposto autor, e outras pelo próprio herói, ele mesmo reduplicado em uma série de metamorfoses.

Ora, se a figura do autor perde-se em mistérios, dado sua sumaríssima biografia, não menos enigmática é a do Conde de Lautréamont, pseudônimo inspirado no personagem homônimo criado por Eugène Sue em Os mistérios de Paris. Dessa forma, a indeterminação entre as figuras de Ducasse, Lautréamont e Maldoror parece realizar a intenção de apagamento do "eu" insistentemente manifesta em sua obra, abrindo espaço para uma poesia "feita por todos".

Semelhante desejo encontra-se expresso na lírica de Murilo Mendes, inclusive em versos escritos bem antes de suas menções mais explícitas à obra de Lautréamont. Vale notar que tal problemática realmente ganha corpo nos livros publicados na década de 1930, sendo particularmente recorrente em poemas de O visionário (1930-1933), A poesia em pânico (1936-1937) e As metamorfoses (1939-1941).

Prova disso está na insistência com que o poeta coloca a questão "quem sou eu?" nesses escritos, valendo-se dela para expor as múltiplas faces de um sujeito lírico que jamais cede à pretensão de compor a unidade de um retrato. É o que sugere, por exemplo, o poema "Olhar sem tempo", de inspiração surrealista, ao responder: "Sou um retrato de antepassado / Sou aquela camisola que vesti / Há muitos anos atrás. / (...) / Sou uma valsa lenta / brotando nos meus ouvidos. / Sou um cadáver, uma visagem / que alguns sujeitos rindo / Levam sem flores num automóvel". Na mesma chave, revelando um eu poroso ao tempo e ao mundo, o poema "Conhecimento" propõe uma resposta em franco tom maldororiano:

14. MENDES. Lautréamont, p. 1.529. 
Quem sou eu? Um cérebro deixado em pasto aos bichos, Sou a fome de mim mesmo e de todos,

Sou o alimento dos outros,

Sou o bem encarcerado e o mal que não germina.

Sou a própria esfinge que me devora. ${ }^{15}$

À promessa de composição de um retrato, o poeta prefere contrapor a própria ideia de decomposição, manifesta tanto na imagem do anônimo cadáver que não inspira lágrimas nem flores aos companheiros quanto na figura de um Édipo derrotado pela esfinge, incapaz de afirmar sua singularidade humana. Assim, distante do herói fundante de nossa cultura - metáfora do homem que toma consciência de si, realizando os desígnios da célebre inscrição grega, "conhece-te a ti mesmo" -, o eu lírico dos poemas de Murilo parece bem mais próximo do herói de Lautréamont, que se indiferencia das coisas e dos seres do mundo quando diz: "É um homem ou uma pedra ou uma árvore que vai começar o quarto canto."

Proximidade que se revela ainda mais significativa ao percebermos que a afirmação de um sujeito em permanente decomposição caminha em paralelo a uma concepção de poesia que também supõe um eu disperso, tal como aparece nessa "Iniciação":
O manto de chumbo voa:
E eu me reconstituí.
Poemas velozes
Explodindo no meu corpo
Batem as hélices
De encontro ao espelho oblongo
Do passado, presente e futuro.

Não por acaso, trata-se do último poema do livro As metamorfoses, que conclui evocando um sujeito novo, reconstituído, para quem se abre a possibilidade de reinventar o mundo a partir de um grau zero. Liberto do "manto de chumbo", ele deseja atualizar um estado inaugural, quando as leis biológicas e sociais ainda não pesavam sobre a vida e o universo só obedecia à dinâmica das metamorfoses. Liberto do próprio tempo - fixado num espelho que encerra passado,

15. MENDES. Olhar sem tempo; e MENDES. Conhecimento, p. 205 e 301.

16. LAUTRÉAMONT. Les chants de Maldoror, p. 685. 
presente e futuro -, ele faz coincidir o momento da criação com o juízo final, para reconhecer as substâncias do mundo e da linguagem:

Refiz a criação,

Os mortos me contemplam,

Seguram de novo a cartilha.

De agora em diante

Não tenho mais praias.

O avião sacode as penas

Para o juízo final,

Novos mundos já se formam.

Notável afinidade com o universo dos Chants de Maldoror, a insinuar os traços daquela curva fugidia que deixa entrever um contato intenso entre os dois poetas, mas um contato paradoxal que imediatamente se dissolve no mundo, tal como um eco, para realizar a vertiginosa dispersão poética sonhada por Lautréamont:

A poesia sou eu,

A poesia é Altair,

A poesia somos nós. ${ }^{17}$

17. MENDES. Iniciação, p. 370-371. 


\section{Traces of Maldoror in Brazil: Lautréamont in Murilo Mendes}

Abstract: As occurred in France - where Lautréamont only became known in the 20th Century-, in Brazil it is also difficult to speak of the repercussions of his poetic prior to Modernism. Chief among the authors of the movement who were open to his voice is Murilo Mendes, who evokes the creator of Maldorar as "the young black sun / that inaugurates our time". Beyond such explicit references, the Brazilian modernist poet also reveals a bedrock affinity with the writings of Ducasse, especially when they plumb the fundaments of identity. If Lautréamont's work manifests a will to erase the "I", opening space for a literature "made by all", a similar desire is expressed in Murilo Mendes, whose poetry insists on the multiple faces of a lyrical self who refuses the project of composing a single portrait.

Keywords: Lautréamont, Murilo Mendes, Maldoror, Ducasse, Brazilian Modernism.

$$
\text { Referências }
$$

ARRIGUCCI, Davi. Arquitetura da memória. In: O cacto $e$ as ruínas. São Paulo: Duas Cidades, 1997.

BARROSO, Ivo. A obra maldita de Lautréamont. O Estado de S. Paulo, São Paulo, 19 mar. 2006. Cultura, p. D4.

BARTHES, Roland. O prazer do texto. Trad. J. Guinsburg. São Paulo: Perspectiva, 1977. p. 49.

CÂMARA, Ruy. Contos de outono. Rio de Janeiro: Record, 2006.

CÂNDIDO, Antônio. Surrealismo no Brasil. In: Brigada ligeira. São Paulo: Editora UNESP, 1992.

FARIAS, José Niraldo de. O surrealismo na poesia de Jorge de Lima. Porto Alegre: EDIPUCRS, 2003.

LAUTRÉAMONT, Conde de. Les chants de Maldoror. In: Euvres poétiques completes. Paris: Robert Laffont, 1980. p. 685.

LAUTRÉAMONT, Conde de. Os cantos de Maldoror. Trad. Cláudio Willer. São Paulo: Iluminuras, 2005. p. 223.

LIMA, Sergio. Alguns dados sobre a construção interessada de uma ausência: a do surrealismo no Brasil ou... "a cada um o seu desejo". Revista Organon, Porto Alegre, Instituto de Letras da Universidade Federal do Rio Grande do Sul, v. 8, n. 22, p. 202, 1994. 
MASSI, Augusto. Murilo Mendes: a obra do poliedro. In: PIZARRO, Ana (Org.). América Latina: Palavra, Literatura e Cultura. São Paulo: Memorial; Campinas: Editora Unicamp, 1995. v. 3.

MENDES, Murilo. Murilo Mendes - o menino experimental. São Paulo: Summus Editorial, 1979.

MENDES, Murilo. André Breton. Retratos-Relâmpagos (1965-1966). In: Poesia e prosa completas. Rio de Janeiro: Nova Aguilar, 1994. p. 1.238.

MENDES, Murilo. Conhecimento. O visionário (1930-1933). In: Poesia e prosa completas. Rio de Janeiro: Nova Aguilar, 1994. p. 205 e 301.

MENDES, Murilo. Homenagem a Jorge de Lima. Parábola (1946-1952). In: Poesia e prosa completas. Rio de Janeiro: Nova Aguilar, 1994. p. 555.

MENDES, Murilo. Iniciação. As metamorfoses (1939-1941). In: Poesia e prosa completas. Rio de Janeiro: Nova Aguilar, 1994. p. 370-371.

MENDES, Murilo. Lautréamont. Retratos-Relâmpagos (1971-1972). In: e prosa completas. Rio de Janeiro: Nova Aguilar, 1994. p. 1.529. . Poesia

MENDES, Murilo. Lautréamont. Ipotesi (1968). In: Poesia e prosa completas. Rio de Janeiro: Nova Aguilar, 1994. p. 1.529.

MENDES, Murilo. Olhar sem tempo. O visionário (1930-1933). In: prosa completas. Rio de Janeiro: Nova Aguilar, 1994. p. 205. . Poesia e

MENDES, Murilo. Uruguai. Poliedro (1965-1966). In: completas. Rio de Janeiro: Nova Aguilar, 1994. p. 1.023.

Poesia e prosa

MERQUIOR, José Guilherme. À beira do antiuniverso debruçado ou introdução à obra de Murilo Mendes. In: MENDES, Murilo. Antologia Poética. Rio de Janeiro: Fontana/INL, 1976.

PAES, José Paulo. O surrealismo na literatura brasileira. In: Gregos e bahianos. São Paulo: Brasiliense, 1985. p. 99-114.

PERRONE-MOISÉS, Leyla. A falência da crítica. São Paulo: Perspectiva, 1973.

PERRONE-MOISÉS, Leyla; RODRÍGUEZ MONEGAL, Emir. Lautréamont austral. Montevideo: Brecha, 1995.

PONGE, Robert (Org.). Surrealismo e Novo Mundo. Porto Alegre: Editora UFRGS, 1999.

RIMBAUD, A.; LAUTRÉAMONT; CORBIÈRE, T.; CROS, C. Euvres poétiques complètes. Paris: Robert Lafont, 1980.

RIPOLL, Ricard (Org.). Lautréamont-l'autre de la Littérature. In: Cahiers Lautréamont, Paris: Association des Amis Passés, présents et futures d'Isidore Ducasse, 2007. v. LXXVII à LXXX. 